traced to that feeling associated with 'the sense of being male or female'.

Finally, the chapter on the ethical aspects of sex-reassignment and its possible consequences for the future, must be mentioned. It was beyond the scope of this collection to include a lengthy tract on the ethical issues. Nevertheless, this chapter is superficial being only an inadequate summary of the problems. It is concluded with a personal recommendation that the operations, when therapeutic, be allowed to proceed.

Unfortunately, Ross continues by urging 'extreme caution' with respect to its recipients bearing (by abdominal surgery) or adopting children. Against this recommendation it can be argued that sex-reassignment is only ethical if transsexuality is a genuine sex/gender disorder. In which case, the sufferer must be perceived as one who has, through no fault of his/her own, been 'trapped' within an unsuitable body, undergone a series of potentially dangerous, painful, therapeutic operations and has been rendered infertile as a result. Within this context it is unjust to declare that the transsexual is therefore ipso facto unsuitable to rear children, which is what Ross implies.

This publication is a reminder of the philosophical objections to current diagnostic techniques for transsexuality, and also of the ethical problems inherent in the use of the sexchange operation as a treatment for the transsexual condition. Hopefully, it will renew and broaden debate of these issues.

HEATHER DRAPER

Part-time Lecturer in Philosophy, Department of Philosophy, Crewe and Alsager College

\section{Ethical Issues in Death and Dying}

Robert $\mathrm{F}$ Weir, editor, 388 pages, New York, Columbia, $\$ 40$ hardcover $\$ 15$ paperback, Columbia University Press, 1986

In this second edition of a text originally published in 1977 the editor has incorporated several new articles together with a series of current legal (USA) examples relevant to the six sections of the book: Truth-telling; Determining and defining death; Selective non-treatment of handicapped newborns; Responsibility regarding treatment of critically ill and dying patients; Euthanasia; and Suicide.

Robert Weir is Professor of
Philosophy at Oklahoma State University where he teaches biomedical ethics. There is a wealth of information contained within this book which should assist discussion of some very basic ethical issues. By concentrating on the dying many of these issues are brought into sharp focus and the selection of articles and court cases does provide many contrasting views on each topic. For example, on truth-telling, the book looks at attitudes amongst patients and doctors and at the way in which they have changed over a sixteenyear period. Whilst many doctors may 'share the truth' in response to patient demand the grounds for doing so are still arbitrary and emotional. The complexity of deciding what a patient wants and needs to know is very well illustrated, with Weir stating that truthtelling is a moral obligation in medicine more than a mere legal requirement or doctor-controlled privilege. He gives three reasons for this: that paternalism is not a sufficient reason for withholding relevant information, that patients are autonomous people, and that the contractual nature of the doctor/patient relationship is founded on trust. Weir writes: 'The point is that patients have a right to the truth and truthfulness communicated with compassion, understandable language, empathy and respect' (page 46).

The section on determining death is interesting but based very much on the American legal situation and therefore not as readily applicable to this country. The section on treatment abatement has a lot of useful information on such areas as 'living wills', the responsibility of a doctor towards hopelessly ill people and the patient's role in decision-making. A very helpful article discusses the 'least worst death' and the ways in which respect for patient autonomy may lead to cruel results not always anticipated by those advocating 'natural death'.

The book is written by an American, for Americans, and must be seen as such. Certain words in the text might require one to reach for the dictionary (USA edition) for clarification (for example 'fiduciary' and 'egregious'). However, it is a useful publication for those who wish to have easier access to some of the legal decisions made in recent years which have affected clinical practice in America and which might influence practice in this country in the next few years.

PETER SPECK Chaplain, Royal Free Hospital London
Care of the Handicapped Newborn: Parental Responsibility and Medical Responsibility

The Catholic Bishops' Joint Committee on Bio-ethical Issues, 19 pages, London, 60p, The Catholic Media Office, 1986

Most mothers dread the possibility of bearing an abnormal baby. The reality of coping with this event is the subject of this booklet which addresses the bioethical management issues which are raised. It is the product of a multidisciplinary working party of the Roman Catholic Church. The underlying assumption of the discussion is the equality of human rights of every baby to the care and support of the community in which he or she is born. An argument is developed to support the contention that it is an illusion to think that judgements about the worthwhileness of a patient's life can form the basis for clinical treatment. Thus the emphasis of the authors is unequivocally to avoid any situation in which the primary object of management decisions results in any hastening of a child's death.

There are sections on the status of the newborn, and the nature of treatments available, discussing the factors which would need to be taken into account in deciding whether or not treatment would be of benefit to a particular baby. Several questions are clearly outlined. They include the burdensome character of some therapies, the realistic prognosis for the child, and the relative availability of resources, be they financial or medical and nursing expertise. Several specific disorders are described in relation to the management strategies adopted; a useful glossary of medical terminology is provided. Spina bifida and Down's syndrome are two conditions which are examined in closer detail since they are frequently encountered. This is a subject area which arouses deep emotions and it is not unusual for many of those involved to experience genuine differences of opinion. Advice is given for some specific situations such as where parents feel their child's rights are not being respected; the paediatrician faced with parents who reject their handicapped child, and the nurse who regards her instructions as being immoral.

The booklet ends with a section on the role of the Church and society, emphasising the dignity of humanity and 